\title{
Large Body Habitus Artifact
}

National Cancer Institute

\section{Source}

National Cancer Institute. Large Body Habitus Artifact. NCI Thesaurus. Code C87031.

An artifact resulting from a patient with a large body size or body mass. 